\title{
RELATIONSHIP BETWEEN PSYCHOLOGICAL RESILIENCE AND SELF-CARE STRATEGIES OF HEALTHCARE PROFESSIONALS DURING COVID-19 PANDEMIC IN LATVIA
}

\author{
Aiva Bundzena-Ervika \\ Rīga Stradiņš University, Latvia \\ Kristīne Mārtinsone \\ Rīga Stradiṇš University, Latvia \\ Viktorija Perepjolkina \\ Rīga Stradiņš University, Latvia \\ Aleksejs Ruža \\ Daugavpils University, Latvia \\ Jel̦ena Koḷesṇikova \\ Rīga Stradiņš University, Latvia \\ Elmārs Rancāns \\ Rīga Stradiņš University, Latvia
}

\begin{abstract}
As the worldwide pandemic of Covid-19 continues, health-care professionals (HCP) have been exposed to different hazards, and there is a need to explore psychological resilience in crisis situations, and to give recommendations for its strengthening. The aim of this study was to examine relationship between psychological resilience and self-care strategies in HCP of Latvia, controlling for gender and age during Covid-19 pandemic, and to determine whether the psychological resilience and self-care strategies differ between HCP and professionals in other fields (POF) unrelated to healthcare. Method. The sample consisted of 1723 employees, who during the state of emergency continued to work in their profession; they were divided in two groups - 77 HCP (18 men, 59 women, age $M=46.23$ (SD = 14.43)) and 1646 POF (720 men, 926 women, age $M=44.98$ (SD = 11.93)) as comparison group. Specific data of national representative cross-sectional online survey $(N=2608)$, performed in July, 2020, were selected - demographic items, 7 items forming Psychological Resilience Scale and 17 item forming Self-care Strategies Questionnaire (consist of 4 scales: "Spiritual resources", "Social support”, "Free time activities”, "Time management”). Results. "Time management” was only predictive for Self-care strategy for psychological resilience in both HCP and POF group. Neither age nor gender predicted psychological resilience in HCP group. No statistically significant differences for major variables between HCP and POF were found. Conclusions. The results suggest that performing such Self-care activity as time management can help to promote psychological resilience of the employees regardless of profession. Given the
\end{abstract}


Bundzena-Ervika et al., 2021. Relationship Between Psychological Resilience and Self-Care Strategies of Healthcare Professionals During Covid-19 Pandemic in Latvia

workload of HCP in pandemic, this is an important result. HCP psychological resilience and used self-care strategies during COVID-19 are not different from POF.

Keywords: free time activities, healthcare professionals, psychological resilience, SARS-CoV2 , social support, spiritual resources, time management.

\section{Introduction}

In March 2020, the government of Latvia as well as others countries in the European Union and elsewhere in the world declared a state of emergency due to the worldwide pandemic of Covid-19. Normal life of society has changed dramatically and, in the May 2020, the European Commission (2020) as a response to the crisis caused by pandemic published a Policy Brief which emphasizes importance of building emotional and social resilience.

While the population was assigned to social distancing, healthcare professionals (HCP) needed to stay alert and continue to take care of population`s health. The World Health Organization (WHO, 2020), governments of nations (e.g. Latvijas Vēstnesis, 2020, 62B) and scientists (Castelnuovo, Giorgio, Manzoni, Treadway, \& Mohiyeddini, 2020) draw special attention to HCP as they have been exposed to different hazards and appropriate action has been settle as necessary to minimize potential damages. Additionally, in Cabinet of Ministry of Latvia Order No. 278 "National Research Program to Mitigate Consequences of COVID-19” a goal has been set to examine psychological resilience in crises situations and to give recommendations and guidelines for its strengthening among the overall population and in specific groups (Latvijas Vēstnesis, 2020, 96D).

Over the past few months, there has been an increase in scientific studies about psychological resilience during COVID-19 and self-care as one of the key links for its promotion. There is a wide variety in how psychological resilience construct has been defined and conceptualized, but its basic meaning is applicable on how individuals or groups can positively adapt to serious adversity (D. Fisher, Ragsdale, \& E. Fisher, 2018). Adversity can vary from experienced difficulties in everyday life till major life events but evaluating positive adaptation context of adversity must be considered (Fletcher \& Sarkar, 2013). Effective and/or healthy functioning despite of experienced difficulties demonstrates psychological resilience (Fisher et al., 2018). Resources and skills promoting greater psychological resilience can be learned (American Psychological Association, n.d., a). Regarding HCP healthy functioning during the COVID-19 pandemic the basic task is to explore mechanisms that would help HCP to demonstrate their psychological resilience in this extraordinary situation. In this study psychological resilience is viewed as a changeable phenomenon, which evolves based on experience and is expressed in (1) faith and conviction to handle every life 
challenge, (2) find a solution for every difficult situation, (3) ability to accept life as it is, (4) ability to maintain internal balance and regain it after crises situations, and (5) sense of security for one's future (Perepjolkina \& Mārtinsone, 2020).

Some studies have described importance of gender and age in relation to psychological resilience. In two extensive studies with 1719 participants aged from 19 to 103 (Lundman, Strandberg, Eisemann, Gustafson, \& Brulin, 2007) and 3265 participants from 17 to 65+ (Portzky, Wagnild, De Bacquer, \& Audenaert, 2010) results showed positive relation between age and psychological resilience, but role of gender was confirmed only by Portzky and colleagues (2010) and only to specific measurement where male participants scored higher. In a study conducted by Gínez-Silva, Astorga and Urchaga-Litago (2019) differences were explored by dividing participants in four age groups - adolescents (age range 1618), young people (age range 19-25), adults-young (age range 26-25), adults (age range 46-65). Results showed that adults were more resilient than adolescents. As regards gender differences, opposite results were found in two groups adolescent males were more resilient than adolescent women, but adult males were less resilient than adult women. More specific way how age may have an impact onto psychological resilience was shown in a study in which older and younger adults were compared. Overall, participants over 64 were more resilient than participants under 26, but in certain aspect of psychological resilience younger adults scored higher (Gooding, Hurst, Johnson, \& Tarrier, 2012). As it can be seen, results showed tendency that age is associated with greater psychological resilience, but at the same time younger individuals can score higher in specific aspects. Association between gender and psychological resilience is ambiguous. If age and gender are relatively fixed potential predictors of psychological resilience, other potentially related factors can be developed, for example, different self-care strategies, and, furthermore, a hypothetical possibility to promote psychological resilience.

Self-care is defined as "the ability of individuals, families and communities to promote health, prevent disease, maintain health, and to cope with illness and disability with or without the support of a healthcare provider" (WHO, 2014). Historically medical ethics have always put emphasis on patient care and have ignored importance of HCP self-care (Irvine, 2009), but significant changes that HCP face in their working lives due to COVID-19 eventually have drawn society's attention to those who help and serve them in their sickness and health (Adams \& Walls, 2020; Pfefferbaum \& North, 2020; Unadkat \& Farquhar, 2020).

Several self-care strategies used by people during pandemic are described in this study. They are as follows: a use of social support, engagement in different free time activities, time management and spiritual resources. Social support is defined as „the provision of assistance or comfort to others, typically to help them 
cope with biological, psychological, and social stressors. It may take the form of practical help (e.g., doing chores, offering advice), tangible support that involves giving money or other direct material assistance, and emotional support that allows the individual to feel valued, accepted, and understood" (American Psychological Association, n.d., b). Social support can be provided by the family, friends and acquaintances, neighbors, co-workers, employers etc. According to Fisher and colleagues (2018), developed heuristic framework for resiliencerelated variables seeking emotional/ instrumental support is included as one of the resilience mechanisms - specific, helping responses to withstand adversity. In a qualitative study on community health workers insights of COVID-19, social support has been mentioned as a supporting resource (Mayfield-Johnson et al., 2020).

Another psychological resilience mechanism, included in the heuristic framework for resilience-related variables, is planning (Fisher et al., 218), which is a part of a self-care strategy - time management. Time management is „the practice of using the time that you have available in a useful and effective way, especially in your work" (Cambridge Dictionary, n.d., a). Time management can be considered as an important self-care strategy because workload and unwholesome rotation schedules are noted as a source of HCP psychological distress during pandemic (Muller et al., 2020). Time management is reflected in effective planning of time, compliance with the daily routine and balanced work and leisure time. Latest gives opportunity to practice another important self-care strategy - free time activities.

Free time activities are attributable to different desirable actions beside work, study etc. (Cambridge Dictionary, n.d., b), for example, doing hobbies, watching TV, serial, movies, reading or listening a book, walks, doing physical activities, sport. As Mayfield-Johnson and colleagues (2020) identified in their qualitative study, different free time activities according to individual wishes (walking, doing hobbies, watching videos etc.) had served as a self-care strategy to community health workers to deal with stress in COVID-19 pandemic. In addition to the mentioned free-time activities, another self-care strategy beneficial for HCP, which can be practiced in free time, is mindfulness meditation (Hofmeyer, Taylor, \& Kennedy, 2020) and is considered as a spirituality practice.

Spirituality is defined as ,a concern for God and sensitivity to religious experience, which may include the practice of a particular religion but may also exist without such practice” (American Psychological Association, n.d., c), it can be practiced through such resources as prayers and religious practices, belief in God and relay on God and His grace, spiritual practices and meditation, support from church and congregation. Spiritual resources have been considered as helpful self-care strategy in time of pandemics (Castañeda \& HernándezCervantes, 2020). 
The latest scientific articles discuss self-care promotion and enhance the HCP psychological resilience in pandemic emphasizing the meaning of self-care process planning (Mills, Ramachenderan, Chapman, Greenland, \& Agar, 2020), ability of the leading specialists to promote subordinate self-care (Hofmeyer, \& Taylor, 2020), different self-care daily practices (such as sleep hygiene, exercise, seeking for help, stay connected with others etc.), mindfulness meditation (Heath, Sommerfield, \& von Ungern-Sternberg, 2020; Hofmeyer et al., 2020). Additionally, in qualitative study about HCP experiences during Covid-19 regarding to psychological resilience social-support and self-management (incl. devoting time to free time activities) strategies was identified as a source to cope with stress in a given situation where HCP needed to work in a new context (participants had no infectious disease expertise), where they experienced heavy workload, exhaustion from protective gear, fear of infection, and powerlessness (Liu et al., 2020). Study conducted by Hou et al. (2020) reports on social support protective relationships with mental health via resilience, thus confirming social support impact on psychological resilience.

As indicated, scientific literature reports on about significance of psychological resilience, self-care and its association in HCP during COVID-19, but as, it can be seen, at the moment there is limited information which would explain the direct impact of specific self-care strategies on psychological resilience during pandemic from a quantitative perspective.

This study was conducted in order to study the psychological resilience and its predictors during the pandemic to make recommendations for its strengthening. The aim of this study was to examine relationship between psychological resilience and self-care strategies in HCP of Latvia, controlling for gender and age, during the Covid-19 pandemic. An additional aim was set to determine whether the psychological resilience and self-care strategies differ between HCP and professionals in other fields (POF) unrelated to healthcare.

\section{Methodology}

\section{Participants and procedure}

This study is a part of a research project „Impact of COVID-19 on health care system and public health in Latvia: ways in preparing health sector for future epidemics”, project No. VPP-COVID-2020/1-0011. Data collection was performed by research company considering ICC/ESOMAR International Code on Market, Opinion and Social Research and Data Analytics in July, 2020. Computer-assisted web interviewing technique was used - participants received individual invitation with a password and a link to the questionnaire on the 
internet (in Latvian or Russian, according to the respondent's choice) by e-mail, questionnaire could be filled at a time chosen by the participant for a specified period of time.

The overall research project survey consisted of 27 thematic sections, for the purpose of this study specific items regarding to demographics (gender, age, education, marital status), psychological resilience and self-care were used.

Participants were selected from a nationally representative sample of Latvia (total $N=2608$, valid $N=2606$ ). The requirements for respondents were: he/she was an employee and during state of emergency continued to work in his/her profession $(N=1723)$. All participants were divided in two groups - healthcare professionals (HCP, $N=77$ ), if they confirmed that they worked in healthcare services, and professionals of other fields unrelated to healthcare (POF, $N=1646$ ) as comparison group. Sample characteristics are reported in Table 1.

\section{Table 1 Socio-demographic Characteristic of Participants}

\begin{tabular}{|l|l|l|}
\hline \multirow{2}{*}{ Characteristic } & $\begin{array}{l}\text { HCP-Sample } \\
N=77\end{array}$ & $\begin{array}{l}\text { POF-Sample } \\
N=1646\end{array}$ \\
\cline { 2 - 3 } & $n(\%)$ & $n(\%)$ \\
\hline Gender: & \multicolumn{2}{|l|}{} \\
\hline Men & $18(23.4)$ & $720(43.7)$ \\
\hline Women & $59(76.6)$ & $926(56.3)$ \\
\hline Age & $M=46.23(S D=14.43)$ & $M=44.98(S D=11.93)$ \\
\hline Education: & \multicolumn{2}{|l}{} \\
\hline $\begin{array}{l}\text { Compulsory education } \\
\text { (9 years of school) }\end{array}$ & 0 & $30(1.8)$ \\
\hline $\begin{array}{l}\text { Secondary / professional } \\
\text { education (12 years of } \\
\text { school) }\end{array}$ & $24(31.2)$ & $515(31.3)$ \\
\hline $\begin{array}{l}\text { Higher education (College } \\
\text { or University degree) }\end{array}$ & $53(68.8)$ & $1101(66.9)$ \\
\hline Marital Status: & \multicolumn{2}{|l}{} \\
\hline Married/engaged/cohabited & $51(66.2)$ & $1135(68.9)$ \\
\hline Single, never married & $10(12.9)$ & $281(17.1)$ \\
\hline Widowed or divorced & $16(20.8)$ & $207(12.6)$ \\
\hline Missing & 0 & $23(1.4)$ \\
\hline
\end{tabular}

This study was fully reviewed and approved by the The Rịga Stradiñs University Research Ethics Committee (act No. 6-1/07/4). 


\section{Measures}

Psychological Resilience Scale (Perepjolkina \& Mārtinsone, 2020) is a 7item measure which was used to assess the individual psychological resilience and was developed for research project „Impact of COVID-19 on healthcare system and public health in Latvia: ways in preparing health sector for future epidemics”, project No. VPP-COVID-2020/1-0011. The respondent was asked to rate the degree to which he or she agrees with the statement on a 5-point scale from 1 (disagree) to 5 (agree), for example, "I believe I can handle any problem in life." A higher grade indicates also a higher level of psychological resilience. In the current study Cronbach`s alpha of the scale was 0.87 .

Self-Care Strategies Questionnaire (SCSQ; Perepjolkina, Koḷesnikova, Ruža, Bundzena-Ervika, \& Mārtinsone, 2020) is 17-item self-report instrument which consists of 4 scales - "Spiritual resources" (4 items, strategies which build upon religious faiths, spiritual practices and church support), "Social support" (5 items, finding support from colleagues, friends, family members, employer, neighbors), "Free time activities" (5 items, strategies related to free time activities, such as physical activities, sport, to go on walks, to do hobbies, TV watching and book reading) and "Time management" (3 items, strategies focused on balancing work and leisure time, effective time management, and compliance with the healthy daily routine). Respondents were asked to assess the extent how helpful was the mentioned supportive mechanism in a state of emergency situation on a 6 - point scale from 1 (did not help at all) to 5 (helped a lot), 0 - was not used. A higher score indicates that strategy was more used and more helpful. In the current study the Cronbach`s alpha of scales was correspondingly 0.83 for "Spiritual resources", 0.87 for "Social support", 0.79 for "Free time activities" and 0.88 for "Time management".

\section{Data analysis}

Statistical analysis was performed using IMB SPSS Statistics software v.25. Cronbach's alpha was calculated to estimate each subscale's reliability. Descriptive statistics were calculated for demographical and main variables for HCP and POF group. The Independent samples T-test was used to test statistical differences between the means of HCP and POF group. Associations between Psychological resilience and Self-care strategies were analyzed by computing Pearson product-moment correlation coefficient, followed by Hierarchical linear regression analysis, with Psychological resilience as a dependent variable and scales of self-care strategies as predictors after controlling for gender and age in the first step. 
Bundzena-Ervika et al., 2021. Relationship Between Psychological Resilience and Self-Care Strategies of Healthcare Professionals During Covid-19 Pandemic in Latvia

\section{Research Results}

\section{Descriptive statistics and group differences}

Table 2 shows descriptive statistics and the Independent samples T-test statistics for major variables. For all five major variables, it was found, that there are no statistically significant differences between the two groups - HCP and POF. In both groups the average scores of Psychological resilience scale was slightly skewed to the high score direction.

Less frequently used self-care strategy in both groups is "Spiritual resources"; $67.5 \%$ in the HCP group and 63.5\% in the POF group reported that they do not use any of self-care activities at all, related to this strategy (they got 0 points in this scale), in comparison to $27.3 \%$ in the HCP group and $19.7 \%$ in the POF group, who got 0 points in "Social support" sub-scale; $9.1 \%$ in the HCP group and $6.9 \%$ in the POF group, who got 0 points in "Free time activities" subscale, and $9.1 \%$ in the HCP group and $14.7 \%$ in the POF group, who got 0 points in "Time management" sub-scale. So, frequency and average tendency analysis revealed, that the most popular self-care strategy in both groups was "Free time activities", and almost the same popular in the HCP group, but slightly less in the POF group, was the "Time management" strategy.

\section{Correlation and regression analysis}

Table 2 Descriptive Statistics, Independent Samples T-test and Pearson Correlations for Major Variables in the HCP Group and POF Group

\begin{tabular}{|l|c|c|c|c|c|}
\hline & 1 & 2 & 3 & 4 & 5 \\
\hline 1. Psychological Resilience & -- & .03 & $.06^{*}$ & $.10^{* *}$ & $.21^{* *}$ \\
\hline 2. Spiritual Resources (SR) & .01 & -- & $.30^{* *}$ & $.23^{* *}$ & $.19^{* *}$ \\
\hline 3. Social Support (SS) & -.04 & $.39^{* *}$ & -- & $.45^{* *}$ & $.39^{* *}$ \\
\hline 4. Free Time Activities (FTA) & $.23^{*}$ & $.27^{*}$ & $.50^{* *}$ & -- & $.59^{* *}$ \\
\hline 5. Time Management (TM) & $.27^{*}$ & $.29^{*}$ & $.39^{* *}$ & $.59^{* *}$ & -- \\
\hline \multirow{2}{*}{ HCP group, $M(S D)$} & 26.16 & 0.60 & 1.68 & 2.60 & 2.79 \\
& $(5.58)$ & $(1.07)$ & $(1.39)$ & $(1.39)$ & $(1.48)$ \\
\hline \multirow{2}{*}{ POF group, $M(S D)$} & 25.74 & 0.78 & 1.94 & 2.73 & 2.71 \\
$T$ & $(4.71)$ & $(1.27)$ & $(1.39)$ & $(1.34)$ & $(1.60)$ \\
\hline
\end{tabular}

Note: ${ }^{* *} p<.01,{ }^{*} p<.05$. Below the diagonal correlation, coefficients obtained in the HCP group (healthcare professionals) are displayed; above the diagonal, correlation coefficients obtained in the POF-group (professionals of other fields unrelated to healthcare) are displayed. Scores of SR, SS, FTA and TM sub-scales of SCSQ can vary from 0 to 5 points. Scores of Psychological Resilience can vary from 7 to 35 points. 
To test associations between psychological resilience and four self-care strategies, Pearson correlations were computed. It was found (Table 2), that in the HCP group only two self-care strategies - "Free time activities" and "Time management" showed a weak positive statistically significant correlation with psychological resilience. In the POF group a weak positive statistically significant correlation was found between psychological resilience and "Time management", and a very weak, but statistically significant correlation between psychological resilience and two more self-care strategies: "Free time activities" and "Social support”.

At the next stage of data analysis, hierarchical linear regression analysis was carried out to find out which of the self-help strategies allow predicting psychological resilience in the HCP group and the POF group after controlling for demographic variables. Psychological resilience scale's score was included as a dependent variable to be predicted by age and gender in Step 1 (Enter method was used), and by "Time management" and "Free time activities" in Step 2 (a Stepwise method was used). This analysis was done for each sample separately.

Obtained results are presented in Table 3 and 4. One can see that in the HCP group in the First step neither age nor gender was predicting Psychological resilience. The model in the First step was not statistically significant (Table 3). In the next step "Time management" was found to be predictive for Psychological resilience, and accounted for $7.8 \%$ of variance in Psychological resilience $(B=1.07, S E=.43, \beta=.28, p=.015, \Delta \mathrm{F}(1,73)=6.15, p=.015)$, but the overall model is not statistically significant $(\mathrm{F}(3,73)=2.09, p=.109)$.

Table 3 Hierarchical Regression Analysis Predicting Psychological Resilience in the HCP Group

\begin{tabular}{|c|c|c|c|c|c|c|c|c|c|}
\hline \multirow[t]{2}{*}{ Step } & \multirow[t]{2}{*}{ Predictor } & \multicolumn{2}{|c|}{$\begin{array}{c}\text { Unstandardized } \\
\text { coefficients }\end{array}$} & \multicolumn{2}{|c|}{$\begin{array}{c}\text { Standardized } \\
\text { coefficients }\end{array}$} & \multirow[t]{2}{*}{$R^{2}$} & \multirow{2}{*}{$\begin{array}{c}R^{2} \\
\text { change }\end{array}$} & \multirow[t]{2}{*}{$F$} & \multirow[t]{2}{*}{$p$} \\
\hline & & $B$ & $S E$ & $\beta$ & $p$ & & & & \\
\hline \multirow[t]{3}{*}{1} & & & & & & .001 & .001 & .05 & .948 \\
\hline & Age & -.01 & .04 & -.03 & .773 & & & & \\
\hline & Gender & -.24 & 1.52 & -.02 & .877 & & & & \\
\hline \multirow[t]{4}{*}{2} & & & & & & .079 & .078 & 2.09 & .109 \\
\hline & Age & -.02 & .04 & -.04 & .702 & & & & \\
\hline & Gender & -.65 & 1.48 & -.05 & .661 & & & & \\
\hline & $\begin{array}{l}\text { Time } \\
\text { Management }\end{array}$ & 1.07 & .43 & .28 & .015 & & & & \\
\hline
\end{tabular}

Note. $\mathrm{N}=77 . \mathrm{SE}=$ standard error of $\mathrm{B}$. Age (years). Gender, $1=$ male, 2 = female. Time management $=$ averaged score $(0-5)$ of Time management sub-scale from SCSQ. 
In the POF group, only age was predictive for Psychological resilience in the first step $(\Delta \mathrm{F}(2,1643)=3.85, p<.022)$ (Table 4). In the next step, "Time management" was found to be predictive for Psychological resilience, and accounted for $4.2 \%$ of variance in Psychological resilience $(\Delta \mathrm{F}(1,1642)=72.56$, $p<.001)$, and the overall model was statistically significant $(\mathrm{F}(3,1642)=26.86$, $p<.001)$.

Table 4 Hierarchical Regression Analysis Predicting Psychological Resilience in the POF Group

\begin{tabular}{|c|c|c|c|c|c|c|c|c|c|}
\hline \multirow[t]{2}{*}{ Step } & \multirow[t]{2}{*}{ Predictor } & \multicolumn{2}{|c|}{$\begin{array}{c}\text { Unstandardized } \\
\text { coefficients }\end{array}$} & \multicolumn{2}{|c|}{$\begin{array}{c}\text { Standardized } \\
\text { coefficients }\end{array}$} & \multirow[t]{2}{*}{$R^{2}$} & \multirow{2}{*}{$\begin{array}{c}R^{2} \\
\text { change }\end{array}$} & \multirow[t]{2}{*}{$F$} & \multirow[t]{2}{*}{$p$} \\
\hline & & $B$ & $S E$ & $\beta$ & $p$ & & & & \\
\hline \multirow[t]{3}{*}{1} & & & & & & .005 & .005 & 3.85 & .022 \\
\hline & Age & .02 & .01 & .06 & .024 & & & & \\
\hline & Gender & .42 & .23 & .04 & .073 & & & & \\
\hline \multirow[t]{4}{*}{2} & & & & & & .044 & .042 & 26.86 & .000 \\
\hline & Age & .01 & .01 & .03 & .177 & & & & \\
\hline & Gender & .05 & .23 & .01 & .815 & & & & \\
\hline & $\begin{array}{l}\text { Time } \\
\text { Management }\end{array}$ & .62 & .07 & .21 & .000 & & & & \\
\hline
\end{tabular}

Note. $N=1646 . S E=$ standard error of $B$. Age (years). Gender, $1=$ men, 2 = women. Time management $=$ averaged score $(0-5)$ of Time management sub-scale from SCSQ.

\section{Discussion}

When this study was performed, the world was experiencing a unique situation - a worldwide pandemic caused by COVID-19 that lasted for months and already had brought significant harmful consequences for the life of society so far. As it is known from previous epidemics or pandemics experiences, in situations like these, the mental health of healthcare professionals (HCP) is at serious risk (Stuijfzand et al., 2020). The crisis has prompted research into psychological resilience, different self-care strategies are being studied as a potential links for its strengthening.

In our study four self-care strategies used in time of emergency were considered - spiritual resources, social support, free time activities and time management. Although spiritual resources can be considered as helpful self-care strategy in the times of pandemics (Castañeda \& Hernández-Cervantes, 2020), the current findings suggest this strategy as a rarely used in a specific population. A possible explanation could be that only $15 \%$ of adults in Latvia reported to be highly religious (Pew Research Center, 2018). This result highlights importance of cultural specifics studying a concept of self-care. 
Most frequently used self-care strategy was a time management and free time activities, which were considered as helpful strategies also in a study conducted by Mayfield-Johnson and colleagues (2020). While due to the organizational issues of the healthcare system there could be difficulties to relieve the workload (Muller et al., 2020), HCP`s time management habits and spending time doing helpful free time activities can be really useful to care of oneself in the time of the pandemic.

Results showed that only time management was found to predict psychological resilience regardless of the type of the occupation. The result about the time management as a predictor of psychological resilience is consistent with Fisher and colleagues (2018) developed model "A Heuristic Framework for Resilience-related Variables", where planning (part of time management) is included as one of the psychological resilience mechanisms. Although the explained variance of psychological resilience with time management was low, this result is still noteworthy and reveals one practical way how to strengthen the psychological resilience.

The most interesting finding was regards the use of social support. In contrast to the previous studies (Hou et al., 2020; Liu et al., 2020), social support did not predict psychological resilience neither in HCP group nor in POF group. Also, in comparison to free time activities and time management, social support was used less often. It is difficult to explain this result, but it might be related to stigmatization regarding psychological resilience in the context of employees. For example, there was a discussion in military context that highlighting role of employee psychological resilience can result in stigmatization about weakness of character if psychological resilience is lower (Adler, 2013), which later Britt and colleagues (2016) extended to the psychological resilience of employees in general, not just to a specific area. It is possible that risk of stigmatization could also be relevant in the field of healthcare. Considering that HCP are a part of the society where ethical norms predict taking care of others no matter what but ignore taking care of themself (Irvine, 2009), there could be a tendency to hide their own difficulties. As the social support, in comparison to other self-care strategies, can send an open message to others about HCP experience of adversity, then the specific study result could occur.

Age did not predict psychological resilience in the HCP group as it is observed in the POF group and as reported in other previous studies. Possible explanation could be the relatively small HCP group size and age range. In other studies, the association between age and psychological resilience has also been observed when the participants' age range was wider (Lundmane et al., 2007; Portzky et al., 2010; Goodin et al., 2010; Gínez-Silva et al., 2019). Gender did not predict psychological resilience neither in any of both study samples; in previous 
studies the association between gender and psychological resilience has also been ambiguous.

It should be noted that overall total dispersion of psychological resilience explained was low. One possible explanation for these results may be due to timing when the data were collected - at that time COVID-19 infection rates in Latvia were very low (Latvijas atvērto datu portāls, 2020) and as a result expected HCP difficulties could be more hypothetical than real. However, concept of psychological resilience provides that some kind of adversity, which demands adaptation, is needed to be experienced. Regarding the used self-care strategies, there is a possibility that the need to use the mentioned self-care strategies to overcome any difficulties related to state of emergency was limited.

There is a number of important limitations to consider. Firstly, regarding the study sample, there were relatively few participants in the HCP group, although participants were selected from a national representative sample of Latvia. For the future work, it would be necessary to increase the sample size and explore current topic depending on specific healthcare profession. Secondly, only self-report methods were used and only self-care strategy - time management (which predicted psychological resilience) explained very small amount of dispersion. Future studies should examine other missing factors. One possible way how to do this is to develop a more comprehensive self-care measurement comparing to measurement used in this study, which was conceptualized, based on available data in the research project. More potential self-care strategies could be included (e.g., professional support).

As psychological resilience affects how a person can adapt to the adversity, objective psychological resilience outcome measures should be included in the future analysis (e.g. mental health indicators, job performance, physiological outcomes). Thirdly, when the data was collected, COVID-19 infection rates in Latvia were very low and there is a chance that the respondents `need to use selfcare strategies was low compared to how it could be with at higher infection rates. A future study in a time with high infection rates is therefore suggested.

In conclusion, the results suggest that performing such self-care activity as time management can help promote employee psychological resilience regardless of profession. This is important result, given HCP workload in time of pandemic and educational events to improve time management skills could be beneficial. There were no difference between HCP and POF regarding to psychological resilience and used self-care strategies in time of emergency during COVID-19 pandemic. It can be concluded that, despite HCP have been exposed to different hazards, their uniqueness in relation to POF regarding to studied variables was not observed. The results of the study complement the existing knowledge on the relationship between self-care strategies and psychological resilience from a quantitative research perspective, reflecting which self-care strategies contribute 
to psychological resilience as well as the importance of specific demographics regarding to psychological resilience.

\section{Acknowledgements}

This study was supported by National research program to lessen the effects of COVID-19, project Nr. VPP-COVID-2020/1-0011, project leader Anda Ķīvīte-Urtāne, Rīga Stradiņ̌̌ University. Work package No. 2 “Associated factors and changes in psychological resilience, mental health in the general population of Latvia during and following the COVID-19 pandemic and directions for future management”, work package leader Elmārs Rancāns.

\section{References}

Adams, J. G., \& Walls, R. M. (2020). Supporting the health care workforce during the COVID19 global epidemic. Jama, 323(15), 1439-1440. https://doi.org/10.1001/jama.2020.3972

Adler, A. B. (2013). Resilience in a military occupational health context: Directions for future research. In R. R. Sinclair \& T. W. Britt (Eds.), Building psychological resilience in military personnel: Theory and practice (223-235). American Psychological Association. https://doi.org/10.1037/14190-010

American Psychological Association. (n.d., a). Resilience. In APA dictionary of psychology. Retrieved from https://dictionary.apa.org/resilience

American Psychological Association. (n.d., b). Social support. In APA Dictionary of Psychology. Retrieved from https://dictionary.apa.org/social-support

American Psychological Association. (n.d., c). Spiritual resources. In APA Dictionary of Psychology. Retrieved from https://dictionary.apa.org/spirituality

Britt, T., Shen, W., Sinclair, R., Grossman, M., \& Klieger, D. (2016). How Much Do We Really Know About Employee Resilience? Industrial and Organizational Psychology, 9(2), 378-404. https://doi.org/10.1017/iop.2015.107

Cambridge Dictionary. (n.d., a) Time management. In Cambridge Dictionary. Retrieved from https://dictionary.cambridge.org/dictionary/english/time-management

Cambridge Dictionary. (n.d., b). Free time activities. In Cambridge Dictionary. Retrieved from https://dictionary.cambridge.org/dictionary/english/free-time

Castañeda, R. F. G., \& Hernández-Cervantes, Q. (2020). Self-care and spirituality in times of contingency due to covid-19. Cogitare enferm. 25, e73518, 2020. http://dx.doi. org/10.5380/ce.v25i0.73518

Castelnuovo, G., De Giorgio, A., Manzoni, G. M., Treadway, D. C., \& Mohiyeddini, C. (2020). Psychological, Behavioral and Interpersonal Effects, and Clinical Implications for Health Systems of the Coronavirus (COVID-19) Pandemic: a call for research. Frontiers in Psychology, 11, 2146. https://doi.org/10.3389/fpsyg.2020.02146

European Commission. (2020). Protect, prepare and transform Europe: recovery and resilience post COVID-19 (ESIR Policy Brief No.1). https://ec.europa.eu/info/sites/ info/files/research_and_innovation/groups/esir/ec_rtd_esir-recovery-resiliencecovid19.pdf 
Bundzena-Ervika et al., 2021. Relationship Between Psychological Resilience and Self-Care Strategies of Healthcare Professionals During Covid-19 Pandemic in Latvia

Fisher, D. M., Ragsdale, J. M., \& Fisher, E. C. (2018). The importance of definitional and temporal issues in the study of resilience. Applied psychology, 68(4), 583-620. https://doi.org/10.1111/apps.12162

Fletcher, D., \& Sarkar, M. (2013). Psychological resilience: A review and critique of definitions, concepts, and theory. European psychologist, 18(1), 12. https://doi.org/ 10.1027/1016-9040/a000124

Gínez-Silva, M. J., Astorga, C. M., \& Urchaga-Litago, J. D. (2019). Resiliencia psicológica a través de la edad y el sexo. Revista INFAD de Psicología. International Journal of Developmental and Educational Psychology, 4(1), 85-94. https://doi.org/10.17060/ ijodaep.2019.n1.v4.1513

Gooding, P. A., Hurst, A., Johnson, J., \& Tarrier, N. (2012). Psychological resilience in young and older adults. International journal of geriatric psychiatry, 27(3), 262-270. https://doi.org/10.1002/gps.2712.

Heath, C., Sommerfield, A., \& von Ungern-Sternberg, B. S. (2020). Resilience strategies to manage psychological distress among healthcare workers during the COVID-19 pandemic: a narrative review. Anaesthesia, 75(10), 1364-1371. https://doi.org/ 10.1111/anae. 15180

Hofmeyer, A., \& Taylor, R. (2020). Strategies and resources for nurse leaders to use to lead with empathy and prudence so they understand and address sources of anxiety among nurses practicing in the era of COVID-19. Journal of Clinical Nursing. https://doi.org/10.1111/jocn.15520

Hofmeyer, A., Taylor, R., \& Kennedy, K. (2020). Knowledge for nurses to better care for themselves so they can better care for others during the Covid-19 pandemic and beyond. Nurse Education Today. https://doi.org/10.1016/j.nedt.2020.104503

Hou, T., Zhang, T., Cai, W., Song, X., Chen, A., Deng, G., \& Ni, C. (2020). Social support and mental health among health care workers during Coronavirus Disease 2019 outbreak: A moderated mediation model. Plos one, 15(5), e0233831. https://doi.org/10.1371/journal. pone.0233831

Humphreys, Lloyd G. and Montanelli, Richard G. (1975). An investigation of the parallel analysis criterion for determining the number of common factors. Multivariate Behavioral Research, 10, 193-205.

Irvine, C. (2009). The ethics of self-care. In T.R. Cole, T.J. Goodrich, E.R. Gritz (eds), Faculty health in academic medicine (pp. 127-146). Humana Press. https://doi.org/10.1007/9781-60327-451-7_10

Liu, Q., Luo, D., Haase, J. E., Guo, Q., Wang, X. Q., Liu, S., ... \& Yang, B. X. (2020). The experiences of health-care providers during the COVID-19 crisis in China: a qualitative study. The Lancet Global Health. https://doi.org/10.1016/S2214-109X(20)30204-7

Latvijas atvērto datu portals. (2020). COVID-19 izmeklējumi, apstiprinātie gadījumi un iznākumi. Retrieved from https://data.gov.lv/dati/lv/dataset?q=covid-19

Lundman, B., Strandberg, G., Eisemann, M., Gustafson, Y., \& Brulin, C. (2007). Psychometric properties of the Swedish version of the Resilience Scale. Scandinavian Journal of Caring Sciences, 21(2), 229-237. https://doi.org/10.1111/j.1471-6712.2007.00461.x

Mayfield-Johnson, S., Smith, D. O., Crosby, S. A., Haywood, C. G., Castillo, J., BryantWilliams, D., ... \& Wennerstrom, A. (2020). Insights on COVID-19 From Community Health Worker State Leaders. The Journal of ambulatory care management, 43(4), 268277. https://doi.org/10.1097/JAC.0000000000000351

Mills, J., Ramachenderan, J., Chapman, M., Greenland, R., \& Agar, M. (2020). Prioritising workforce wellbeing and resilience: What COVID-19 is reminding us about self-care and 
staff support. Palliative Medicine, 34(9), 1137-1139. https://doi.org/10.1177/ 0269216320947966

Muller, A. E., Hafstad, E. V., Himmels, J., Smedslund, G., Flottorp, S., Stensland, S. Ø., Stroobants, S., Van de Velde, S., \& Vist, G. E. (2020). The mental health impact of the covid-19 pandemic on healthcare workers, and interventions to help them: A rapid systematic review. Psychiatry research, 293, 113441. https://doi.org/10.1016/j.psychres. 2020.113441

Par finanšu līdzekḷu piešķiršanu no valsts budžeta programmas "Līdzekḷi neparedzētiem gadījumiem". (2020). Latvijas Vēstnesis, 62B, 27.03.2020. https:/likumi.lv/ta/id/ 313515-par-finansu-lidzeklu-pieskirsanu-no-valsts-budzeta-programmas-lidzeklineparedzetiem-gadijumiem

Par valsts pētījumu programmu Covid-19 seku mazināšanai. (2020). Latvijas Vēstnesis, 96D, 20.05.2020. https://likumi.lv/ta/id/314858-par-valsts-petijumu-programmu-covid-19seku-mazinasanai

Perepjolkina, V., Koḷesnikova, J., Ruža, A., Bundzena-Ervika, A., \& Mārtinsone, K. (2020). Development and Psychometric Properties of the Self-Care Strategies Questionnaire. [Manuscript submitted for publication]. Rīgas Stradiņš University.

Perepjolkina, V. \& Mārtinsone, K. (2020). Development and preliminary validation of the Psychological Resilience Scale [Manuscript submitted for publication]. Rīgas Stradiņš University.

Pew Research Center. (2018). How religious is your country. Retrieved from https://www.pewresearch.org/interactives/how-religious-is-your-country/

Pfefferbaum, B., \& North, C. S. (2020). Mental health and the Covid-19 pandemic. New England Journal of Medicine. https://doi.org/10.1056/NEJMp2008017

Portzky, M., Wagnild, G., De Bacquer, D., \& Audenaert, K. (2010). Psychometric evaluation of the Dutch Resilience Scale RS-nl on 3265 healthy participants: a confirmation of the association between age and resilience found with the Swedish version. Scandinavian journal of caring sciences, 24 Suppl 1, 86-92. https://doi.org/10.1111/j.14716712.2010.00841.x

Stuijfzand, S., Deforges, C., Sandoz, V., Sajin, C. T. C. T., Jaques, C., Elmers, J., \& Horsch, A. (2020). Psychological Impact of an Epidemic/Pandemic on the Mental Health of Healthcare Professionals: A Rapid Review. https://doi.org/10.21203/rs.3.rs-30156/v1

Unadkat, S., \& Farquhar, M. (2020). Doctors' wellbeing: self-care during the covid-19 pandemic. BMJ (Clinical research ed.), 368, m1150. https://doi.org/10.1136/bmj.m1150

World Health Organization. (2014). Self-care for health: WHO Regional Office for South-East Asia. Retrieved from https://apps.who.int/iris/handle/10665/205887

World Health Organization. (2020). Keep health workers safe to keep patients safe: WHO. Retrieve from https://www.who.int/news/item/17-09-2020-keep-health-workers-safe-tokeep-patients-safe-who 